\begin{tabular}{|c|c|}
\hline Citation & $\begin{array}{l}\text { Lötsch, F, Auer-Hackenberg, L. (2015), } \\
\text { Adherence of patients to long-term medication: a cross-sectional study } \\
\text { of antihypertensive regimens in Austria } \\
\text { Wiener Klinische Wochenschrift, } 127(9-10), 379-384 \text {. }\end{array}$ \\
\hline Archived version & $\begin{array}{l}\text { Post-print. Author manuscript: the content is virtually identical to the content } \\
\text { of the published paper, but without the final typesetting by the publisher }\end{array}$ \\
\hline Published version & http://dx.doi.org/10.1007/s00508-015-0782-y \\
\hline Journal homepage & http://link.springer.com/journal/508 \\
\hline Author contact & $\begin{array}{l}\frac{\text { Fabienne.dobbels@med.kuleuven.be }}{\text { Sabina.degeest@med.kuleuven.be }} \\
\underline{\text { Sabina.degeest@unibas.ch }} \\
\text { + } 32(0) 16373402 \\
\text { + } 32 \text { (0)16373294 } \\
\text { + } 41 \text { (0)612670916 }\end{array}$ \\
\hline IR & $\begin{array}{l}\text { https://lirias.kuleuven.be/cv?u=U0015258 } \\
\text { https://lirias.kuleuven.be/cv?u=U0005386 }\end{array}$ \\
\hline
\end{tabular}

(article begins on next page) 


\section{Adherence of patients to long-term medication: A cross sectional study of antihypertensive regimens in Austria}

Felix Lötsch ${ }^{1,2}$, Lorenz Auer-Hackenberg' ${ }^{1}$, Mirjam Groger ${ }^{1,2}$,

Valerie Morrison ${ }^{3}$, Emily Holmes ${ }^{4}$, Sahdia Parveen ${ }^{3}$, Catrin Plumpton ${ }^{2}$, Wendy Clyne ${ }^{5}$, Sabina de Geest ${ }^{6}$, Fabienne Dobbels ${ }^{6}$, Bernard Vrijens ${ }^{7}$, Przemyslaw Kardas ${ }^{8}$, Dyfrig Hughes ${ }^{4}$ and Michael Ramharter ${ }^{1,2}$

${ }^{1}$ Department of Medicine I, Division of Infectious Diseases and Tropical Medicine, Medical University of Vienna

2Institut für Tropenmedizin, Universität Tübingen, Tübingen, Germany ${ }^{3}$ School of Psychology, Bangor University, United Kingdom

${ }^{4}$ Centre for Health Economics \& Medicines Evaluation, Bangor University, United Kingdom

${ }^{5}$ Keele University, United Kingdom

${ }^{6}$ University of Leuven, Belgium

${ }^{7}$ AARDEX Group Ltd., Belgium

${ }^{8}$ Medical University of Lodz, Poland

Corresponding Author: Assoc. Prof. Dr. Michael Ramharter, DTM\&H Department of Medicine I, Division of Infectious Diseases and Tropical Medicine 
Medical University of Vienna

Waehringer Guertel 18-20

A-1090 Wien

+4314040044400

michael.ramharter@meduniwien.ac.at

Keywords: adherence, arterial hypertension, medication

Schlüsselwörter: Adhärenz, Hypertension, Medikation

Keywords: adherence, arterial hypertension, medication Schlüsselwörter: Adhärenz, Hypertension, Medikation 


\section{ABSTRACT}

\section{Objective:}

The objective of this study was to evaluate adherence and causes for non-adherence to antihypertensive therapy in Austrian patients. A special focus was laid on social parameters and behavioural theories.

\section{Methods:}

Patients were invited via advertisements in community pharmacies in Austria to complete an online survey. Inclusion criteria were an age of 18 years or older, a diagnosis of arterial hypertension and a current prescription of antihypertensive medication. Adherence was measured by the 4-item Morisky scale. Non-adherence was defined by at least one point in the Morisky scale. Several demographic, social and behavioural parameters were analysed as potential co-variables associated with adherence.

\section{Results:}

323 patients completed the online survey of which 109 (33.7\%) met the criteria for nonadherence. In a multivariable model self-efficacy and age were associated with adherence, whereas intention and barriers were linked to non-adherence. 56 patients (17.3\%) were classified as intentionally non-adherent.

\section{Conclusion:}

This study demonstrates that non-adherence affects an important proportion of patients in the treatment of arterial hypertension. Young age was a particularly important risk factor for non-adherence and this patient population is therefore in need of special attention. Modifiable risk factors were identified which could help improving the treatment of arterial hypertension and potentially other chronic conditions. 


\section{ZUSAMMENFASSUNG}

Ziel:

Das Ziel dieser Studie war die Erhebung der Therapieadhärenz bei Patienten mit arteriellem Bluthochdruck in Österreich, und deren Ursachen, mit besonderem Augenmerk auf sozialen Parametern und behavioralen Theorien

\section{Methoden:}

Patienten wurden in öffentlichen Apotheken an Hand von Postern und anderem Informationsmaterial zum Ausfüllen eines Online-Fragebogens eingeladen. Eingeschlossen wurden Patienten ab einem Mindestalter von 18 Jahren, mit Bluthochdruckerkrankung und einer aktuellen Verschreibung von antihypertensiven Medikamenten. Die Adhärenz wurde mit Hilfe der 4-teiligen Morisky Skala gemessen. Ab einer bejahend beantworteten Frage galt der Patient als nicht adhärent. Weiters wurden demographische, soziale und behaviorale Parameter erhoben, um deren Zusammenhang mit Therapieadhärenz zu untersuchen.

\section{Resultate:}

323 Patienten konnten rekrutiert werden, wovon 109 (33.7\%) als nicht adhärent klassifiziert wurden. In einem multivariablen Model zeigten sich „self-efficacy“ und Alter mit Adhärenz verbunden, während „intention“ und „barriers“ mit fehlender Adhärenz assoziiert waren. 56 Patienten (17.3\%) wurden als absichtlich nicht-adhärent klassifiziert.

\section{Fazit:}

Diese Studie zeigt, dass mangelhafte Adhärenz ein gewichtiges Problem in der Therapie von Bluthochdruckerkrankungen darstellt. Besonders bei jungen Menschen scheint die Therapie-Adhärenz schlecht $\mathrm{zu}$ sein. Es konnten jedoch auch modifizierbar Risikofaktoren identifiziert werden. Zukünftige Studien sollten sich auf die Entwicklung und Evaluierung von Interventionen konzentrieren, die diese Risikofaktoren beeinflussen. 


\section{INTRODUCTION}

Over the last decades important progress in medical and pharmaceutical sciences led to the development of new efficacious treatments for diverse chronic conditions. However, the ultimate impact of any drug treatment - often measured as the effectiveness - also depends on the patients' adherence to it. Treatments with high efficacy in clinical trials may turn out to be only moderately effective due to incomplete compliance with recommended dosing regimens in real world settings. Non-adherence was therefore identified as a major public health problem by constituting a barrier to the effective, safe and cost-effective use of drugs (1). Conclusively, the World Health Organization (WHO) reported non-adherence as a worldwide medical problem associated with excess morbidity, mortality and unnecessary costs (2). WHO defines adherence "as the extent to which a person's behaviour - taking medication, following a diet, and/or executing lifestyle changes - corresponds with agreed recommendations from a health care provider" (2). In arterial hypertension - defined as a systolic blood pressure of $140 \mathrm{mmHg}$ or above and / or a diastolic blood pressure of $90 \mathrm{mmHg}$ or above - lack of compliance and non-adherence to prescribed medicines is a major reason for unsatisfying therapeutic outcomes and therefore a major challenge (3). Similar to other chronic conditions including diabetes and overweight, a main reason for problems in patients' adherence is the asymptomatic nature of the disease. Other previously reported factors contributing to non-adherence include the long-term disease course of hypertension and thus the necessity for lifelong treatment and multiple daily dosing (4, 5).

Improving the adherence to therapeutic regimens could substantially improve therapeutic outcomes especially in high-income countries, where effective drugs are widely available for everybody. It may prove most cost effective to increase the effectiveness of already licensed drugs by improving patient adherence rather than focussing on developing ever new therapeutic products. A better understanding of causes of non-adherence is however necessary to ultimately improve effectiveness of current drugs. Thus, the aim of this study was to evaluate adherence to long-term medication in Austria and determine its causes with a special focus on social parameters and behavioural theories. 


\section{METHODS}

Data presented in this article stem from the European Union funded project "Ascertaining Barriers for Compliance: policies for safe, effective and cost-effective use of medicines in Europe" (ABC). Cumulative data for the entire European cohort were published in June 2012 in the Final Study Report of the ABC Project and in "Value in Health" (in press). This manuscript describes in detail findings of this survey restricted to Austria.

Patients were recruited via advertisements (posters and printed material) in community pharmacies across Austria, which were randomly selected from a list provided by the national prescription pricing authority. 1272 pharmacies were contacted. Patients were eligible if they were 18 years of age or older, had a diagnosis of arterial hypertension, were currently prescribed medication against arterial hypertension and were selfresponsible for drug-administration. Exclusion criteria were lack of consent, presence of a self-reported psychiatric condition and living in a nursing home or similar facility. The questionnaire was completed via a web-based survey tool provided by SurveyMonkey.com.

\section{Measuring Adherence}

In this study, adherence was measured by the 4-item Morisky Medication Adherence Scale (MMAS-4). The MMAS-4 is the most frequently used questionnaire measuring adherence to medication. This scale, originally designed to evaluate medication adherence in hypertensive patients, has been validated and was found to be reliable in a variety of medication adherence studies $(6,7)$.

Patients were categorized as non-adherent if they answered one or more question of the MMAS-4 with "yes". They were classified as intentionally non-adherent when either item 3 or 4 or both were answered with "yes" (see also table 1). The MMAS-4 is shown in table 2.

\section{Measurement of variables \& instruments used}

The Stanford Self-Rated Health Scale was used to measure health status; the Revised Life Orientation Test (LOT-R) was used to determine optimism (8); the Beliefs about Medicines Questionnaire (BMQ-S11) was applied to evaluate beliefs about medicine (9); to measure attitudes, normative beliefs, barriers, facilitators, intention and self-efficacy, a theory of planned behaviour (TPB) questionnaire was used. TPB is a theory in 
psychology about the link between beliefs and behaviour (10). A questionnaire of the European Task Force on Patient Evaluation in General Practice (EUROPEP) was used to measure satisfaction with the practitioner and her / his practice (11); the Building Research Initiative Group: Chronic Illness Management and Adherence in Transplantation (BRIGHT) for barriers and social support $(12,13)$ and the Brief Illness Perception Questionnaire (BIPQ) were applied to assess parameters of illnessperception (14).

\section{Ethical Considerations}

Ethical approval was obtained by the national ethics committee in Austria (590/2011). Participants provided informed consent by checking a box in the online survey to confirm that they had read and understood all participant information. Access to the survey was denied if the box was not checked. SurveyMonkey®, where the questionnaire responses were stored initially, guaranteed data safety. SurveyMonkey® has signed up to the Safe Harbor agreement. This agreement was created to enable the transfer of 'personal data' between the EU and USA following the introduction of the EU's Data Protection Directive (1995). SurveyMonkey® was asked in written to completely delete survey data from its servers after the termination of the survey.

\section{Data analysis}

The primary outcome of this study was the estimation of the percentage of nonadherent patients defined as patients having answered "yes" to at least one of the 4 items of the Morisky questionnaire. For binominal variables a Fisher's test were applied to calculate differences in distribution between adherent and non-adherent patients. For continuous variables, a Mann-Whitney test was computed. Binary logistic regression analysis was performed to compute a multivariate model including parameters with a significant difference in distribution between adherent and non-adherent patients. Complete case analysis was used. 95\% confidence intervals were derived using the normal approximation of the binomial distribution. Statistical analysis was performed with “R”, version 3.0.2. 


\section{RESULTS}

323 participants completed the questionnaire. 178 (55.1\%) were men and 145 (44.9\%) women. Median age was 62 years (25th-75th percentile: 51-69y; range: $25-89 y$ ). For more demographic data see table 2.

In the overall study population, 109 (33.7\%) had a Morisky-score of 1 or more and were therefore classified as non-adherent. 56 patients (17.3\%) were classified as intentionally non-adherent.

\section{Factors influencing non-adherence}

In univariable analysis, young age was associated with non-adherence. The rate of nonadherence was also significantly higher in working patients or students compared to retired or unemployed ones. Conversely, adherent patients were prescribed a higher number of different drugs ( $p=0.001)$, tablets per day $(p=0.008)$ and had more items on the last prescription ( $\mathrm{p}=0.028)$.

Patients classified as adherent had a high score in the necessity section of the Beliefs About Medicine Questionnaire, the attitude, normative beliefs, intention and self efficacy section of the Theory of Planned Behaviour Questionnaire and the illness consequences (i.e. "How much does your illness affect your life?"), illness timeline (i.e. "How long do you think your illness will continue?"), personal control (i.e. "How much control do you feel you have over your illness?"), treatment control (i.e. "How much do you think your treatment can help your illness?") and illness coherence (i.e. "How well do you feel you understand your illness?") part of the BIPQ. Satisfaction with the treating practitioner and his practice were significantly higher in adherent patients. In contrast, the use of cost coping strategies and a high score in the barriers-section of the BRIGHT questionnaire were associated with non-adherence.

In a multivariable model, older age (OR 0.94; 95\% CI $0.89-0.99 ; \mathrm{p}=0.02$ ) and selfefficacy (i.e. the personal sense of control; TPB) (OR 0.66; 95\% CI $0.52-0.83$; p < 0.001) were associated with adherence, whereas intention (TPB) (OR 1.44; 95\% CI 1.04 - 2.16; $\mathrm{p}=0.04$ ) and barriers (BRIGHT) (OR 1.11; 95\% CI 1.02 - 1.23; $\mathrm{p}=0.02$ ) were linked to non-adherence (see table 3).

\section{Intentional non-adherence}

Intentional non-adherence was significantly more frequent in participants reporting regular employment or students than in retired or unemployed. $(15.0 \%$ vs. $33.7 \%$; $\mathrm{p}=$ 
0.01). Use of cost coping strategies was associated with intentional non-adherence (Mann-Whitney-U: $\mathrm{p}=0.048$ ). Scores in the variables attitudes, intention, self-efficacy and normative believes (TPB) and illness timeline (i.e. people think that their illness will continue for a long time) and treatment control (i.e. people think that treatment can help the illness) (BIPQ) were lower in patients classified as intentionally non-adherent. Also a high score in barriers (BRIGHT) was significantly associated with intentional nonadherence. Due to the small case numbers, multivariable analysis was omitted.

\section{DISCUSSION}

Non-adherence to antihypertensive medication was $33.7 \%$ in our patient population. These data are therefore proof of an important potential for improvement of patient care even in high-income countries, where universal access to healthcare is guaranteed. The observed proportion is considerably higher than for other medical conditions with a more symptomatic disease course including multiple sclerosis or follow-on therapy after acute coronary syndrome $(15,16)$. However, other European countries had considerably higher proportions of non-adherence accounting for up to $70 \%$ of patients in Hungary (17).

In our multivariable analysis we identified four risk factors significantly influencing the adherence to antihypertensive medication.

Young age was shown to be linked to non-adherence. Although this is a per-se nonmodifiable factor, young patients may require special counselling to improve adherence. This may be of particular importance because young patients are most likely to benefit from improved adherence to antihypertensive drugs.

Among the modifiable risk factors low "self-efficacy" (TPB), high intention (TPB) and high barriers (BRIGHT) were identified as predictors for non-adherence. Self-efficacy is the personal sense of control and its crucial importance in several different settings was shown previously (18-20). People who believe their action can solve a problem become more inclined to do so and feel more committed to their decisions (21). It can be influenced by a person's own experience, the experiences of others, social persuasion and someone's psychological status(22). Also barriers including side effects of drugs or forgetfulness should be specifically addressed in all patients with hypertension to optimize therapeutic outcomes. This also shows that personal beliefs and social influences are more important for adherence than the clinical situation or factors attributable to the disease itself. Paradoxically, we also found high intention to be 
predictive for non-adherence. This finding stands in contrast to literature(23) and we speculate that it might be an artefact of statistical analyses, especially because intention was already very high in the overall study population (median 10 out of 10 points).

Our results also show the crucial role of allowing enough time in personal communications between the practitioner and patients to make interventions possible and successful. Such risk factors can be influenced by a range of interventions. Selfefficacy might be increased by programs such as the herz.leben program, which was established in Styria, Austria. It provides structured training for patients on several aspects of the treatment and control of the disease (e.g. adequate nutrition, physical exercise, blood measurement training) and was shown to significantly decrease blood pressure and the risk of a cardiovascular event.(24)

Limitations of this study included the way of data acquisition possibly leading to a selection bias in the study population. Questionnaires and responses were provided via internet leading to the impossibility to confirm diagnoses or responses. Importantly, patient groups without internet access were most likely underrepresented in this survey. The so-called self-serving bias, defined as the distortion of cognition of perception in order to maintain self-esteem, might have confounded our results and the impact of non-responders was not assessable during this survey. However, the anonymity of this survey may also be regarded as strength as responders are less likely to conceal non-adherence compared to personal interviews.

In summary this study reports a high proportion of non-adherence to antihypertensive medication in Austria, but identifies modifiable variables influencing adherence. This survey may provide important insights for the treatment of arterial hypertension and other chronic conditions. Future studies should evaluate specific interventions to improve adherence to therapeutic regimens. This could help to ameliorate effectiveness and efficiency of existing drugs.

\section{STATEMENT OF CONFLICT OF INTEREST}

The authors declare that they have no conflict of interest.

\section{FUNDING}


This work was supported by the European Union's Seventh Framework Programme FP7/2007-2013 “Ascertaining Barriers to Compliance (ABC) project” under grant agreement number 223477 


\section{REFERENCES}

1. Osterberg L, Blaschke T. Adherence to medication. $\mathrm{N}$ Engl $\mathrm{J}$ Med. 2005;353(5):487-97.

2. Sabaté E, WHO Adherence to Long Term Therapies Project., Global Adherence Interdisciplinary Network., World Health Organization. Dept. of Management of Noncommunicable Diseases. Adherence to long-term therapies : evidence for action. Geneva: World Health Organization; 2003. 196 p. p.

3. Myers MG. Compliance in hypertension: why don't patients take their pills? Cmaj. 1999;160(1):64-5.

4. Iskedjian M, Einarson TR, MacKeigan LD, Shear N, Addis A, Mittmann N, et al. Relationship between daily dose frequency and adherence to antihypertensive pharmacotherapy: evidence from a meta-analysis. Clin Ther. 2002;24(2):302-16.

5. Hansson L. 'Why don't you do as I tell you?' Compliance and antihypertensive regimens. Int J Clin Pract. 2002;56(3):191-6.

6. Morisky DE, Green LW, Levine DM. Concurrent and predictive validity of a selfreported measure of medication adherence. Med Care. 1986;24(1):67-74.

7. Morisky DE, Ang A, Krousel-Wood M, Ward HJ. Predictive validity of a medication adherence measure in an outpatient setting. J Clin Hypertens (Greenwich). 2008;10(5):348-54.

8. Scheier MF, Carver CS, Bridges MW. Distinguishing optimism from neuroticism (and trait anxiety, self-mastery, and self-esteem): a reevaluation of the Life Orientation Test. J Pers Soc Psychol. 1994;67(6):1063-78.

9. Horne R. The beliefs about medicines questionnaire: The development and evaluation of a new method for assessing the cognitive representation of medication. Psychology and Health. 1999;14:1-24.

10. Ajzen I, Mannheimer Zentrum f( ${ }^{*}$ r Europ@Pische Sozialforschung. The theory of planned behavior : habit, perceived control, and reasoned action. Mannheim: Mannheimer Zentrum f( ${ }^{*}$ r Europ(CPische Sozialforschung; 2000. 18 p. p.

11. Grol R, Wensing M, Mainz J, Ferreira P, Hearnshaw H, Hjortdahl P, et al. Patients' priorities with respect to general practice care: an international comparison. European Task Force on Patient Evaluations of General Practice (EUROPEP). Fam Pract. 1999;16(1):4-11.

12. Dobbels F, Moons P, Abraham I, Larsen CP, Dupont L, De Geest S. Measuring symptom experience of side-effects of immunosuppressive drugs: the Modified Transplant Symptom Occurrence and Distress Scale. Transpl Int. 2008;21(8):764-73.

13. Schmid-Mohler G, Thut MP, Wuthrich RP, Denhaerynck K, De Geest S. Nonadherence to immunosuppressive medication in renal transplant recipients within the scope of the Integrative Model of Behavioral Prediction: a cross-sectional study. Clin Transplant. 2010;24(2):213-22.

14. Broadbent E, Petrie KJ, Main J, Weinman J. The brief illness perception questionnaire. J Psychosom Res. 2006;60(6):631-7.

15. Devonshire V, Lapierre Y, Macdonell R, Ramo-Tello C, Patti F, Fontoura P, et al. The Global Adherence Project (GAP): a multicenter observational study on adherence to disease-modifying therapies in patients with relapsing-remitting multiple sclerosis. Eur J Neurol. 2011;18(1):69-77.

16. Eagle KA, Kline-Rogers E, Goodman SG, Gurfinkel EP, Avezum A, Flather MD, et al. Adherence to evidence-based therapies after discharge for acute coronary syndromes: an ongoing prospective, observational study. Am J Med. 2004;117(2):73-81. 
17. The-ABC-Project-team. Ascertaining Barriers for Compliance: policies for safe, effective and cost-effective use of medicines in Europe. 2012.

18. Giles M, McClenahan C, Cairns E, Mallet J. An application of the Theory of Planned Behaviour to blood donation: the importance of self-efficacy. Health Educ Res. 2004;19(4):380-91.

19. Strecher VJ, DeVellis BM, Becker MH, Rosenstock IM. The role of self-efficacy in achieving health behavior change. Health Educ Q. 1986;13(1):73-92.

20. Meyerowitz BE, Chaiken S. The effect of message framing on breast selfexamination attitudes, intentions, and behavior. J Pers Soc Psychol. 1987;52(3):500-10.

21. Conner M, Norman P. Predicting health behaviour : research and practice with social cognition models. Buckingham: Open University Press; 1996. ix, 230 p. p.

22. Bandura A. Self-efficacy : the exercise of control. New York: W.H. Freeman; 1997.

23. Husebo AM, Dyrstad SM, Soreide JA, Bru E. Predicting exercise adherence in cancer patients and survivors: a systematic review and meta-analysis of motivational and behavioural factors. Journal of clinical nursing. 2013;22(1-2):4-21.

24. Perl S, Riegelnik V, Mrak P, Ederer H, Rakovac I, Beck P, et al. Effects of a multifaceted educational program on blood pressure and cardiovascular risk in hypertensive patients: the Austrian herz.leben project. Journal of hypertension. 2011;29(10):2024-30. 
Table 1: The Morisky 4-Item Self-Report MEASURE of Medication-taking behaviour (MMAS-4)

\begin{tabular}{|l|c|c|}
\hline \hline & Yes & No \\
\hline 1. Do you ever forget to take your high blood pressure medicine? & 0 & 1 \\
\hline $\begin{array}{l}\text { 2. Do you ever have problems remembering to take your high blood } \\
\text { pressure medicine? }\end{array}$ & 0 & 1 \\
\hline $\begin{array}{l}\text { 3. When you feel better, do you sometimes stop taking your high blood } \\
\text { pressure medicine? }\end{array}$ & 0 & 1 \\
\hline $\begin{array}{l}\text { 4. Sometimes if you feel worse when you take your high blood pressure } \\
\text { medicine, do you stop taking it? }\end{array}$ & 0 & 1 \\
\hline
\end{tabular}

Use of the (CMMAS is protected by US copyright laws. Permission for use is required. A Licensure agreement is available from: Donald E. Morisky, ScD, ScM, MSPH, Professor, Department of Community Health Sciences, UCLA School of Public Health, 650 Charles E. Young Drive South, Los Angeles, CA 90095-1772, dmorisky@ucla.edu. 
Table 2: Demographic data and missing data for overall study population $(n=323)$

\begin{tabular}{|c|c|}
\hline Variable (\% missing data) & $\begin{array}{c}\text { median }\left(25^{\text {th }}-75^{\text {th }} \text { percentile) or absolute }\right. \\
\text { numbers }(\% \text { of overall population) }\end{array}$ \\
\hline Age (0\%) & $62 y(51-69 y)$ \\
\hline \multicolumn{2}{|l|}{$\operatorname{Sex}(0 \%)$} \\
\hline male & $178(55.1 \%)$ \\
\hline female & $145(44.9 \%)$ \\
\hline \multicolumn{2}{|l|}{ Civil Status (2.2\%) } \\
\hline Married & $209(64.7 \%)$ \\
\hline Single/divorced/widow & $107(33.1 \%)$ \\
\hline \multicolumn{2}{|l|}{ Education $(2.8 \%)$} \\
\hline Primary / secondary & $120(37.2 \%)$ \\
\hline Higher than primary / secondary & $194(60.1 \%)$ \\
\hline \multicolumn{2}{|l|}{ Employment (1.5\%) } \\
\hline Working / Student & $119(36.8 \%)$ \\
\hline Retired / Unemployed & $199(61.6 \%)$ \\
\hline Number of medical conditions, median (1.2\%) & $2(1-3)$ \\
\hline Number of medicines, median $(1.2 \%)$ & $4(2-6)$ \\
\hline Number of tablets per day, median $(2.8 \%)$ & $4(2-7)$ \\
\hline \multicolumn{2}{|l|}{ Dosage frequency $(0.9 \%)$} \\
\hline Once daily & $114(35.3 \%)$ \\
\hline Two times daily & $110(34.1 \%)$ \\
\hline Three times daily & $96(29.7 \%)$ \\
\hline$>$ three times daily & $0(0 \%)$ \\
\hline \multicolumn{2}{|l|}{ Self reported health status $(0.6 \%)$} \\
\hline Poor & $23(7.1 \%)$ \\
\hline Fair & $96(29.7 \%)$ \\
\hline Good & $128(39.6 \%)$ \\
\hline Very good / excellent & $74(22.9 \%)$ \\
\hline Number of items on last prescription, median $(8.7 \%)$ & $4(2-6)$ \\
\hline \multicolumn{2}{|l|}{ Do you pay for prescription $(0.9 \%)$} \\
\hline No & $26(8.0 \%)$ \\
\hline Yes, prescription charge & $282(87.3 \%)$ \\
\hline Yes, full cost & $12(3.7 \%)$ \\
\hline \multicolumn{2}{|l|}{ Affordability problem $(0.9 \%)$} \\
\hline No & $231(71.5 \%)$ \\
\hline Yes & $89(27.6 \%)$ \\
\hline Use of cost coping strategies, mean (3.1\%) & 0.9585 \\
\hline Optimism - life orientation test $(0=$ low, $24=$ high $)(9.0 \%)$ & $15(13-18)$ \\
\hline Necessities of medicines $(5=\mathrm{low}, 25=$ high $)(8.6 \%)$ & $19(16.75-22)$ \\
\hline Concerns about medicines $(6=$ low, $30=$ high $)(10.8 \%)$ & $15(12-19)$ \\
\hline $\begin{array}{l}\text { Attitudes - theory of planned behaviour }(7=\text { low, } \\
35=\text { high })(12.3 \%)\end{array}$ & $28(25-32)$ \\
\hline $\begin{array}{l}\text { Normative beliefs - theory of planned behaviour }(3=\text { low, } \\
15=\text { high })(12.3 \%)\end{array}$ & $15(12-15)$ \\
\hline $\begin{array}{l}\text { Barriers - theory of planned behaviour }(1=\text { low, } 5=\text { high }) \\
(10.2 \%)\end{array}$ & $1(1-3.75)$ \\
\hline $\begin{array}{l}\text { Facilitators - theory of planned behaviour }(3=\text { low, } \\
15=\text { high })(13.6 \%)\end{array}$ & $8(5-11)$ \\
\hline $\begin{array}{l}\text { Intention - theory of planned behaviour }(2=\text { low, } \\
10=\text { high })(10.2 \%)\end{array}$ & $10(9-10)$ \\
\hline Self efficacy - theory of planned behaviour $(2=$ low, & $8(6-10)$ \\
\hline
\end{tabular}




\begin{tabular}{|c|c|}
\hline \multicolumn{2}{|l|}{$10=$ high $)(7.4 \%)$} \\
\hline \multicolumn{2}{|l|}{ Practitioner $(7.4 \%)$} \\
\hline General practitioner / family physician & $163(50.5 \%)$ \\
\hline Other & $136(42.1 \%)$ \\
\hline \multicolumn{2}{|l|}{ Gender of practitioner $(\mathbf{1 0 . 2 \% )}$} \\
\hline Female & $114(35.3 \%)$ \\
\hline Male & $176(54.5 \%)$ \\
\hline $\begin{array}{l}\text { EUROPEP satisfaction with practitioner }(17=\text { low, } \\
\text { 85=high) }(18.9 \%)\end{array}$ & $70(62-79)$ \\
\hline $\begin{array}{l}\text { EUROPEP satisfaction with practice }(6=\text { low, } 30=\text { high }) \\
(16.1 \%)\end{array}$ & $24(21-29)$ \\
\hline BRIGHT barriers $(0=$ low, $60=$ high $)(45.8 \%)$ & $5(1-8.5)$ \\
\hline BRIGHT social support $(0=$ low, $28=$ high $)(13.0 \%)$ & $2(0-4)$ \\
\hline \multicolumn{2}{|l|}{ BIPQ } \\
\hline Illness consequences $(8.0 \%)$ & $5(2-8)$ \\
\hline Illness timeline $(8.7 \%)$ & $10(8-10)$ \\
\hline Personal control $(8.0 \%)$ & $7(4-8)$ \\
\hline Treatment control $(9.0 \%)$ & $9(7-10)$ \\
\hline Identity $(9.6 \%)$ & $5(2.75-7)$ \\
\hline Concern about illness $(9.3 \%)$ & $5(3-8)$ \\
\hline Illness coherence $(10.8 \%)$ & $8(6-10)$ \\
\hline Emotional representations $(9.6 \%)$ & $4(2-6)$ \\
\hline \multicolumn{2}{|l|}{ Income $(11.5 \%)$} \\
\hline Salaries / wages & $93(28.8 \%)$ \\
\hline Pensions / benefits / others & $193(59.8 \%)$ \\
\hline \multicolumn{2}{|l|}{ Total Income (deciles) $(9.0 \%)$} \\
\hline $1-4$ & $96(29.7 \%)$ \\
\hline $5-7$ & $103(31.9 \%)$ \\
\hline $8-10$ & $57(17.6 \%)$ \\
\hline Not willing to provide & $38(11.8 \%)$ \\
\hline \multicolumn{2}{|l|}{ Income perception $(8.0 \%)$} \\
\hline Comfortable & $65(20.1 \%)$ \\
\hline Coping & $141(43.7 \%)$ \\
\hline Difficult / very difficult & $54(16.7 \%)$ \\
\hline Not willing to provide & $37(11.5 \%)$ \\
\hline \multicolumn{2}{|l|}{ Ease of borrowing $(8.7 \%)$} \\
\hline Very difficult, quite difficult & $122(37.8 \%)$ \\
\hline Neither easy nor difficult & $85(26.3 \%)$ \\
\hline Quite easy, very easy & $38(11.8 \%)$ \\
\hline Not willing to provide & $50(15.5 \%)$ \\
\hline
\end{tabular}


Table 3: Multivariable model investigating association between various variables and non-adherence

\begin{tabular}{|c|c|c|c|}
\hline Variable & OR & $95 \% \mathrm{CI}$ & p-value \\
\hline Age & 0.94 & $0.89-0.99$ & 0.022 \\
\hline Number of medicines & 0.93 & $0.67-1.25$ & 0.622 \\
\hline Number of tablets per day & 1.00 & $0.85-1.13$ & 0.983 \\
\hline Employment status & 1.96 & $0.56-7.32$ & 0.299 \\
\hline Number of medical conditions & 0.96 & $0.64-1.37$ & 0.829 \\
\hline Use of coping strategies & 0.95 & $0.77-1.14$ & 0.619 \\
\hline Necessities (BMQ) & 0.92 & $0.79-1.07$ & 0.303 \\
\hline Attitudes (TPB) & 0.97 & $0.88-1.08$ & 0.620 \\
\hline Normative believes (TPB) & 0.94 & $0.79-1.11$ & 0.458 \\
\hline Self efficacy (TPB) & 0.66 & $0.52-0.83$ & $<0.001$ \\
\hline Intention (TPB) & 1.44 & $1.04-2.16$ & 0.044 \\
\hline Illness consequences (BIPQ1) & 0.91 & $0.77-1.08$ & 0.282 \\
\hline Illness timeline (BIPQ2) & 0.95 & $0.74-1.21$ & 0.661 \\
\hline Personal control (BIPQ3) & 0.99 & $0.82-1.19$ & 0.897 \\
\hline Treatment control (BIPQ4) & 1.08 & $0.80-1.46$ & 0.614 \\
\hline Illness coherence (BIPQ7) & 0.92 & $0.75-1.12$ & 0.395 \\
\hline Satisfaction of practitioner & 1.03 & $0.97-1.09$ & 0.399 \\
\hline Satisfaction with practice & 1.05 & $0.91-1.22$ & 0.486 \\
\hline Barriers (BRIGHT) & 1.12 & $1.02-1.23$ & 0.025 \\
\hline
\end{tabular}

